\title{
A New Approach For Smart Soil Erosion Modelling: Integration of Empirical And Machine Learning Models
}

Mohammadtaghi Avand ( $\nabla$ mt.avand70@gmail.com )

Tarbiat Modares University https://orcid.org/0000-0001-7196-5051

Maziar Mohammadi

Tarbiat Modares University

Fahimeh Mirchooli

Tarbiat Modares University

Ataollah Kavian

Sari Agricultural Sciences and Natural Resources University

John P Tiefenbacher

Texas State University

\section{Research Article}

Keywords: Machine learning, RUSLE, Soil erosion, Spatial modelling, Talar watershed.

Posted Date: September 29th, 2021

DOl: https://doi.org/10.21203/rs.3.rs-809330/v1

License: (9) This work is licensed under a Creative Commons Attribution 4.0 International License. Read Full License 


\section{A New Approach for Smart Soil Erosion Modelling: Integration of Empirical \\ and Machine Learning Models}

3 Mohammadtaghi Avand ${ }^{* 1 a, b}$, Maziar Mohammadi², Fahimeh Mirchooli ${ }^{3}$, Ataollah Kavian $^{4}$,

${ }^{1 a}$ Department of Watershed Management and Engineering, Faculty of Natural Resources, Tarbiat Modares

7 University, Tehran, Iran

$8{ }^{1 \mathrm{~b}}$ Department of Forests, Rangelands, and Watershed Management Engineering, Kohgiluyeh \& Boyer

9 Ahmad Agricultural and Natural Resources Research and Education Centre, AREEO, Yasouj, Iran.

$10 \quad{ }^{2}$ Department of Watershed Management and Engineering, Faculty of Natural Resources, Tarbiat Modares

11 University, Tehran, Iran

$12{ }^{3}$ Department of Watershed Management and Engineering, Faculty of Natural Resources, Tarbiat Modares

13 University, Tehran, Iran

$14{ }^{4}$ Faculty of Natural Resources, Sari Agricultural Sciences and Natural Resources University, Sari, Iran

$15 \quad{ }^{5}$ Department of Geography, Texas State University, San Marcos, TX, USA

Corresponding author: mt.avand70@gmail.com

\section{Abstract}

Despite advances in artificial intelligence modelling, the lack of soil erosion data and other watershed information is still one of the important factors limiting soil-erosion modelling. Additionally, the limited number of parameters and the lack of evaluation criteria are major

22 disadvantages of empirical soil-erosion models. To overcome these limitations, we introduce a 23 new approach that integrates empirical and artificial intelligence models. Erosion-prone locations 24 (erosion $\geq 16$ tons/ha/year) are identified using RUSLE model and a soil-erosion map is prepared 
25 using random forest (RF), artificial neural network (ANN), classification tree analysis (CTA), and

26 generalized linear model (GLM). This study uses 13 factors affecting soil erosion in the Talar

27 watershed, Iran, to increase prediction accuracy. The results reveal that the RF model has the

28 highest prediction performance (AUC=0.95, Kappa=0.87, Accuracy=0.93, and Bias=0.88),

29 outperforming the three machine-learning models. The results show that slope angle, land use/land

30 cover, elevation, and rainfall erosivity are the factors that contribute the most to soil erosion

31 propensity in the watershed. Curvature and topography position index (TPI) were removed from

32 the analysis due to multicollinearity with other factors. The results can be used to improve the

33 identification of hot spots of soil erosion, especially in watersheds for which soil-erosion data are

34 limited.

35

36 Keywords: Machine learning, RUSLE, Soil erosion, Spatial modelling, Talar watershed.

1. Introduction

40 Human-induced soil erosion is considered to be the most widespread form of (Pournader et al. 412018 ) and main contributor (> $85 \%$ ) to land degradation (Tang et al. 2015). The United Nations

42 Food and Agriculture Organization has determined that soil erosion is one of the 10 main threats 43 to soils globally world (Chalise et al. 2019) and that it contributes to food insecurity (Phinzi et al. 44 2020). Several studies have highlighted the on- and off-site consequences of soil erosion, including 45 water quality, agricultural productivity, and sedimentation of rivers, which cause numerous social 46 and economic issues (Sharma et al., 2011; Pournader et al., 2018). The quantification of soil 47 erosion, identification of the most important factors contributing to soil-erosion inducement, and 
48 the mapping of areas that are most prone to soil erosion are required for successful design and 49 implementation of soil and water conservation projects.

50 Numerous quantitative models designed for different uses and requiring diverse data have been 51 proposed for to estimate soil erosion. Some, like Water Erosion Prediction Project Model (WEPP) 52 (Nearing et al. 1989), Areal Non-point Source Watershed Environment Response Simulation 53 (ANSWERS) (Beasley et al. 1980), and the European Soil Erosion Model (EuroSEM), are physical 54 models. Some, like the Universal Soil Loss Equation (USLE) (Wischmeier and Smith 1978), 55 Revised Universal Soil Loss Equation (RUSLE) (Renard et al. 1991), have been used to assess soil 56 erosion empirically. RUSLE is the model most commonly used to assess erosion as it is simple to 57 use, it is relatively inexpensive, and it is reliable (Pham et al. 2018). This model predicts soil loss 58 based on rainfall erosivity, topography, soil erodibility, vegetation cover, and land use 59 management techniques (Vaezi et al. 2008). Koirala et al. (2019) and Atoma et al. (2020) are 60 examples of its applications. Combining RUSLE with remote sensing data and a geographical 61 information system (GIS) can make erosion assessments time-efficient and cost-effective, 62 particularly for large watersheds. Numerous studies have used this combination to map soil erosion 63 (Nyesheja et al. 2019; Mohammed et al. 2020), and to assess the influences of different factors 64 like soil particle size (Wang et al. 2008), crop types (Ruysschaert et al. 2007), and land use 65 (Vanacker et al. 2019).

66 RUSLE is challenged by the impacts of other soil characteristics and environmental features 67 (Gayen et al. 2019). To resolve these issues, machine learning (ML) algorithms have been tested and are becoming more popular because they improve accuracy, performance, and have other strengths (Mousavi et al. 2017). Models using artificial neural-networks (ANN), logistic regression 70 (LR) models, random forest models, generalized linear models (GLMs), and classification tree 
71 analysis (CTA) have been developed to assess the spatial relationships between conditioning

72 factors and soil erosion rates.

73 This study integrates RUSLE with ML to analyze soil erosion at the watershed scale. Soil erosion

74 is assessed in the Talar watershed, Mazandaran Province, Iran to determine the locations of erosion

75 hot spots. The identified hot spots are used to increase soil-erosion prediction accuracy with ML

76 models. The ML models tested include RF, ANN, GLM, and CTA and they are used to explore

77 the relationships between erosion and several conditioning factors. The most important innovation

78 in this research is the use of RUSLE to improve hot spot identification to increase ML accuracy.

79

80

\section{2. Methods}

\section{$82 \quad$ 2.1. Description of study area}

83 The 210000 ha Talar watershed extends from mountains to the Caspian Sea. The south-to-north

84 flowing Talar River passes through the city of Ghaemshahr and across a lowland plain before 85 emptying into the Caspian (Fig. 1). Much of the watershed is rangeland and forest, especially in

86 the highlands. Irrigated agriculture, dry farming, and urban/residential are the other primary land 87 uses in the study area. The highest elevation is $3910 \mathrm{~m}$ above sea level (asl) at Shaljmar Zardin in 88 the southwestern part of the watershed. The lowest point is at the outlet of the Talar river at $217 \mathrm{~m}$ 89 asl (Fig. 1). Due to the topography and proximity to the sea, precipitation is orographic and 90

91 the southern and southwestern parts of the watershed, but at elevations above $2400 \mathrm{~m}$, rainfall 92 decreases, particularly in the southeastern part of the basin due to reduced moisture availability. 93 There are 58 types of soil with varying physical and chemical properties in the region. In addition, 
95 (Mohammadi et al. 2020).

96

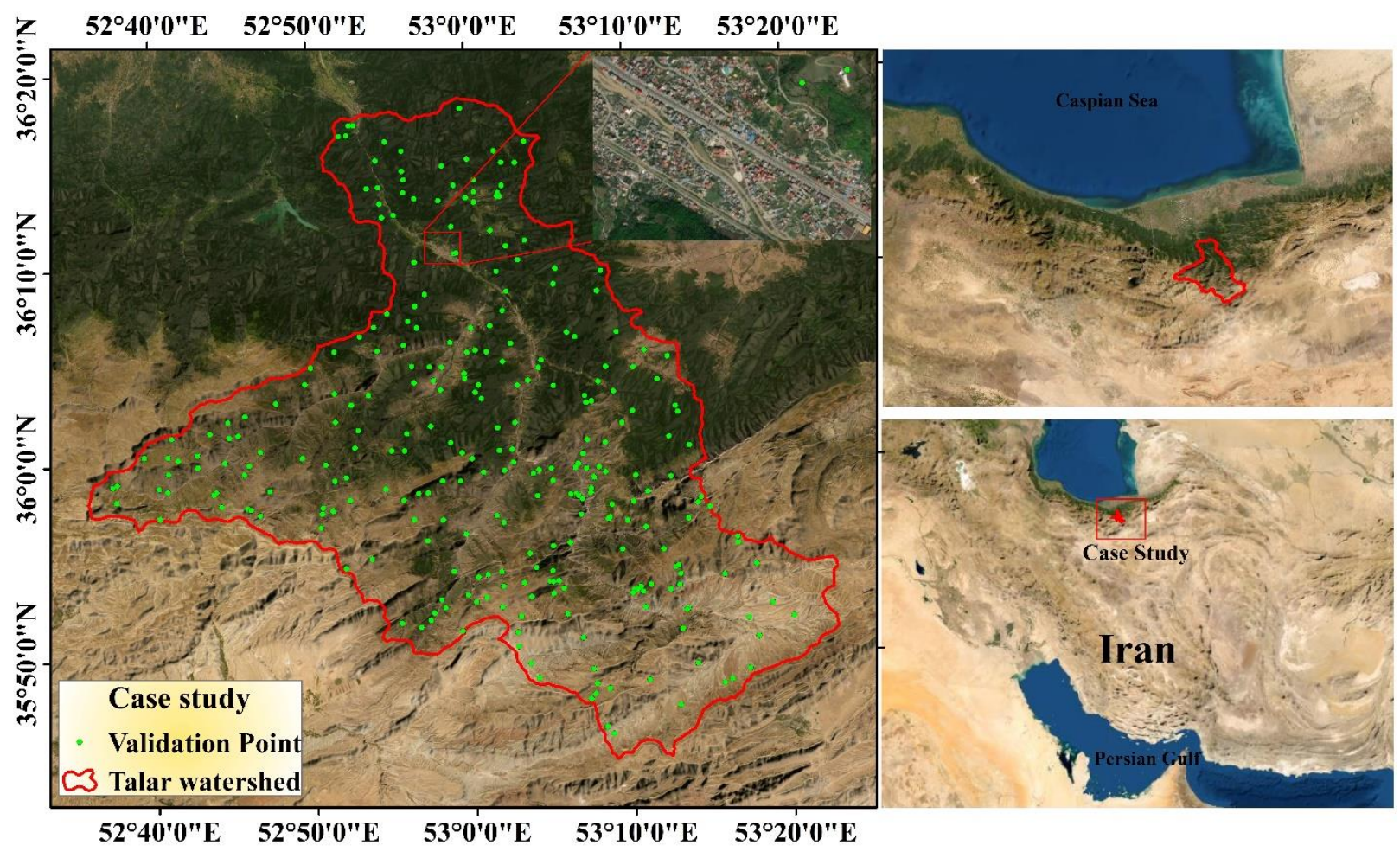

Fig. 1 The location of study area in the Mazandaran province, northern Iran

\subsection{Methods and software}

101 Spatial modelling of soil erosion in the Talar watershed was performed by integrating RUSLE 102 with ML models in 5 main steps: (1) Preparation of parameters (R, K, LS, C and P) and erosion 103 map using RUSLE in GIS; (2) Extraction of locations of severe erosion locations (> 16 tons/ha/yr) 104 for model training; (3) Preparation of the parameters that affect erosion and the ML models using 105 training data in $\mathrm{R}$ software; (4) Removal of parameters with similar performance through 
multicollinearity analysis; (5) Introduction of the relative importance of the parameters to cause

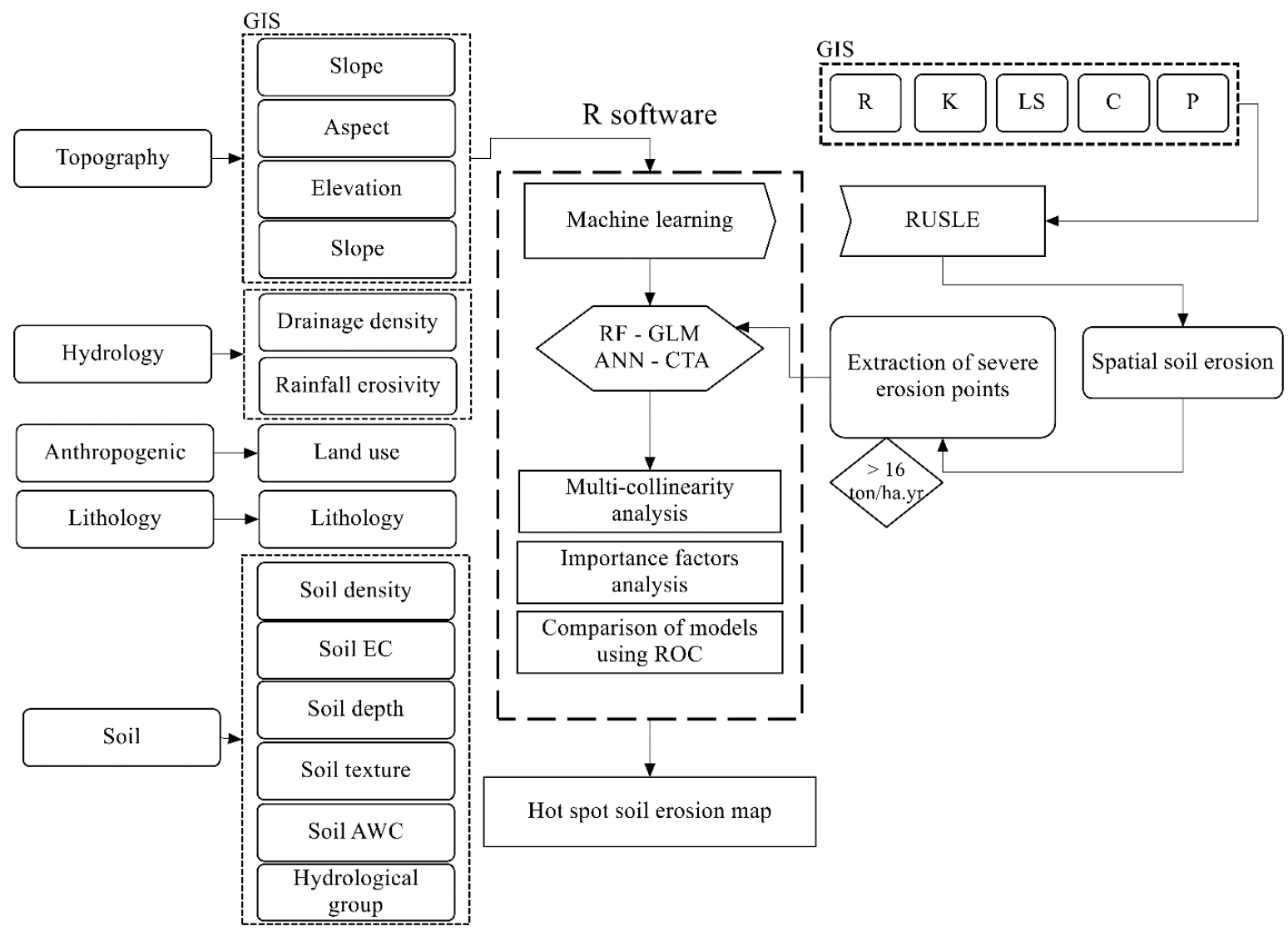

Fig. 2 A flowchart of this study

\subsection{Spatial data-sets}

113 The watershed boundary was delineated using a digital elevation model (DEM) having a resolution

114 of $30 \mathrm{~m}$ with the Arc-SWAT extension in ArcGIS (Table 1). The rainfall records were obtained

115 from seven rainfall monitoring stations in the watershed to calculate rainfall erosivity in RUSLE.

116 Land uses were classified from a satellite image (OLI) using supervised classification in ENVI

117 version 5.3. RUSLE was mapped (Fig. 3a). The RUSLE map was classified by erosion rates and 
118 areas $>16$ ton/ha/yr are considered zones of severe erosion. These areas were extracted and 500

119 locations were randomly selected as training points for the ML models (Fig. 3b). The average soil

120 erosion rate in Iran is $15-20$ tons/ha/yr. This is 3-4 times higher than the global average due to

121 climatic, topographic and anthropogenic conditions (Karamidehkordi, 2010; Arekhi et al., 2012).

122 Table 1. Variables, types, and sources of data used in study

\begin{tabular}{|c|c|c|c|c|}
\hline Data & Data item & Type & Period & Source \\
\hline DEM & $\begin{array}{l}\text { Raster map (30m } \\
\text { resolution) }\end{array}$ & Raster & & $\begin{array}{c}\text { Iran National Cartographic } \\
\text { Center }\end{array}$ \\
\hline Geology & $\begin{array}{c}\text { Geology map and } \\
\text { information }\end{array}$ & Shape file & 1997 & $\begin{array}{l}\text { Geological Survey \& Mineral } \\
\text { Explorations of Iran (GSI) }\end{array}$ \\
\hline Land use & Land use classes & Raster & 2018 & $\begin{array}{c}\text { USGS (https://earthexplorer. } \\
\text { usgs.gov/) }\end{array}$ \\
\hline Weather data & Observed rainfall & Daily & $2000-2017$ & Iran Meteorological Organization \\
\hline Land cover & Vegetation cover & Shape file & 2017 & (Mohammadi et al., 2017) \\
\hline Soil & $\begin{array}{l}\text { Soil physical and } \\
\text { chemical properties }\end{array}$ & Shape file & 2002 & $\begin{array}{c}\text { (Engineering Services Company } \\
\text { 2002) }\end{array}$ \\
\hline River & Names and tributaries & Shape file & & $\begin{array}{c}\text { Iran National Cartographic } \\
\text { Center }\end{array}$ \\
\hline
\end{tabular}

123 
124

125

126

127

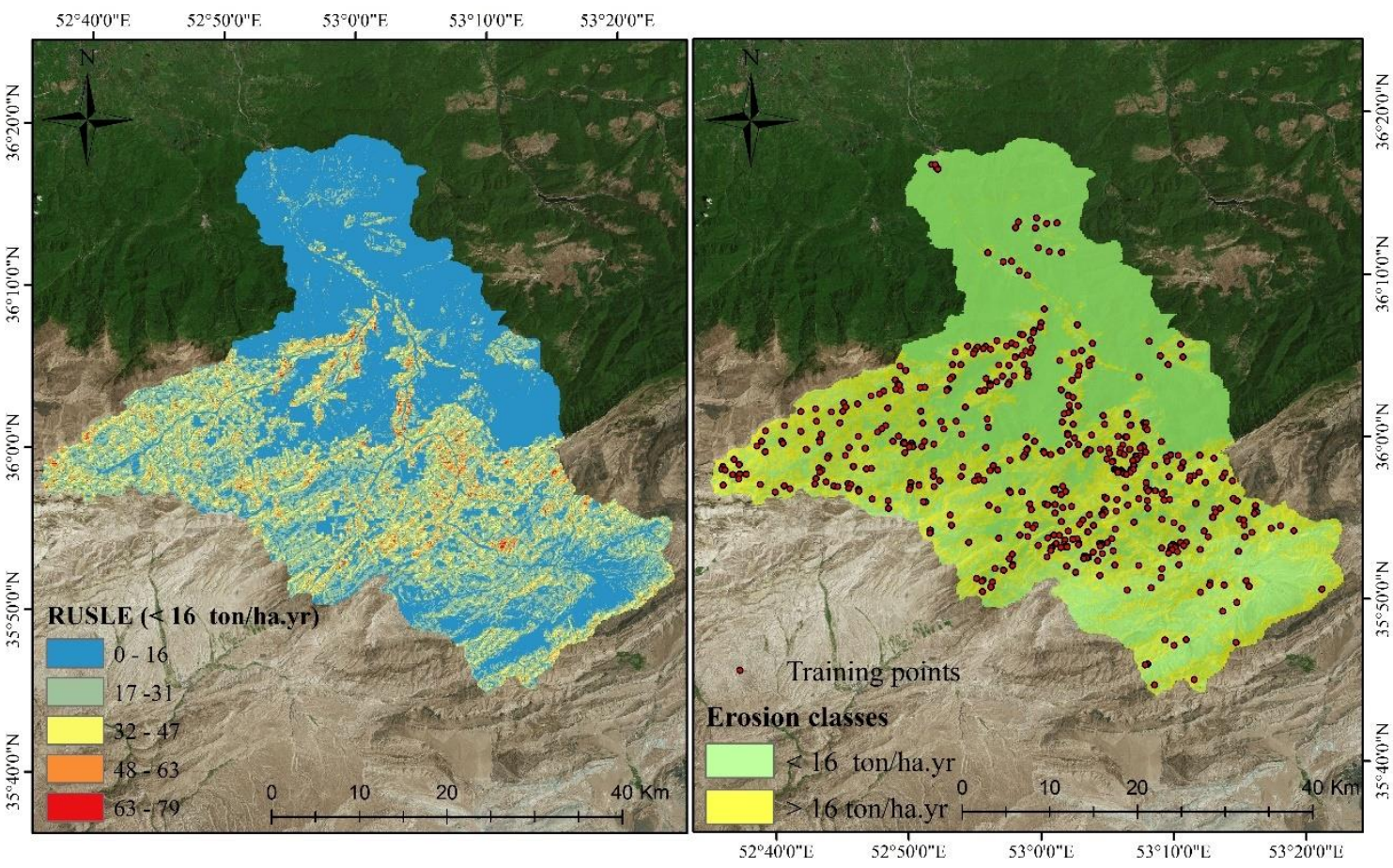

Fig. 3 RUSLE map (a) and training point selection (b)

\subsection{Building Models for Predicting Soil Erosion}

\section{Selection of Predictors}

\section{Topographical factors}

Three topographical factors - slope length, gradient, and shape - are important drivers of erosion due to their influences on the speed and volume of runoff (Bagio et al. 2017). The DEM provided basic land surface data regarding slope, aspect, curvature, drainage area, drainage networks, and topographic indices (Mukherjee et al. 2013). Slope angle, aspect and, elevation were extracted from the DEM and classified in ArcGIS 10.3. Slope angles ranged from 0 to 72 and there are 5 aspect classes from -1 (flat area) and 0 to 359 degrees. Topography controls flow velocity and erosion and deposition rates, and influences erosion through conditions that determine flow convergence and divergence on the land surface (Pourghasemi et al. 2014). 


\section{Lithology and soil factors}

140 Lithology and soil properties also affect soil and land degradation processes like piping and

141 gullying (Bouchnak et al. 2009, Amine et al. 2012, Faulkner 2013, Lei et al. 2020). Data that

142 describe lithology (Table 2) and soil properties were entered for electrical conductivity (EC), soil

143 available water (SAW), texture, density, depth, and soil hydrological group into the GIS.

144

145 Table 2. Geological units of the Talar watershed

\begin{tabular}{|c|c|c|c|}
\hline & Unit & Description & Area covered $(\%)$ \\
\hline 1 & Murm & Marl and gypsiferous marl with sandstone intercalations & 0.03 \\
\hline 2 & Mc & Conglomerate and sandstone & 0.07 \\
\hline 3 & Olc,s & Conglomerate and sandstone & 0.13 \\
\hline 4 & Pgkc & Coarse grained, polygenic conglomerate with sandstone intercalations & 0.26 \\
\hline 5 & Mur & Marl, gypsiferous marl, sandstone and conglomerate & 0.26 \\
\hline 6 & Qft2 & Low level pediment fan and valley terrace deposits & 0.34 \\
\hline 7 & K1bvt & Basaltic volcanic tuff & 0.36 \\
\hline 8 & $\mathrm{Jd}$ & Argillaceous limestone with intercalations of calcareous shale & 0.37 \\
\hline 9 & $\mathrm{~K}_{2} \mathrm{l}_{2}$ & Thick - bedded to massive limestone & 0.56 \\
\hline 10 & Db-sh & Undifferentiated limestone, shale and marl & 0.58 \\
\hline 11 & $\operatorname{Pr}$ & Medium - bedded to massive limestone & 0.62 \\
\hline 12 & Qft1 & High level piedmont fan and valley terrace deposits & 0.68 \\
\hline 13 & $\mathrm{Czl}$ & Undifferentiated unit, composed of dark red micaceous siltstone and sandstone & 0.70 \\
\hline 14 & E11 & Nummulitic limestone & 0.71 \\
\hline 15 & K211 & Hyporite bearing limestone & 0.78 \\
\hline 16 & $\mathrm{Jk}$ & Conglomerate, sandstone and shale with plant remains and coal seams & 0.82 \\
\hline 17 & $\mathrm{Pz}$ & Undifferentiated lower Paleozoic rocks & 1.12 \\
\hline 18 & Ktzl & Thick bedded to massive, white to pinkish orbitolina bearing limestone & 1.79 \\
\hline 19 & $\mathrm{Cb}$ & Alternation of dolomite, limestone and variegated shale & 2.14 \\
\hline 20 & TRe & Thick bedded grey o'olitic limestone & 2.63 \\
\hline 21 & $\mathrm{Ku}$ & Upper cretaceous, undifferentiated rocks & 3.34 \\
\hline 22 & Ek & Well bedded green tuff and tophaceous shale & 3.76 \\
\hline 23 & Qm & Swamp and marsh & 4.63 \\
\hline 24 & $\mathrm{~J} 1$ & Light grey, thin - bedded to massive limestone & 5.94 \\
\hline 25 & $\mathrm{Plc}$ & Polymictic conglomerate and sandstone & 7.48 \\
\hline 26 & E1m & Marl, gypsiferous marl and limestone & 8.36 \\
\hline 27 & $\mathrm{Mm}, \mathrm{s}, 1$ & Marl, calcareous sandstone, sandy limestone and minor conglomerate & 10.92 \\
\hline 28 & TRJs & Shale and sandstone (Shemshak formation) & 40.62 \\
\hline
\end{tabular}




\section{Hydrologic factors}

148 Hydrological factors like drainage density, river buffer, and precipitation also influence erosion 149 and affect sediment-transport processes (Wulf et al. 2010, Ali et al. 2014). Drainage density was 150 determined from the DEM in the GIS. Rainfall erosivity was determined from precipitation data 151 recorded at seven stations.

152

153 Anthropogenic factors

154 Land use is one of the most important anthropogenic factors in soil degradation. Development of 155 agricultural and residential areas, and unscientific and unsustainable agricultural operations for 156 livelihoods, over grazing and deforestation have led to increasing degradation and pressure on soil 157 resources, especially in developing countries (Tadesse et al. 2017, Tang et al. 2020). The major 158 land use types in the Talar watershed are rangeland, forestland, dry or rain-fed agriculture, irrigated 159 agriculture, and urban/residential land use. 


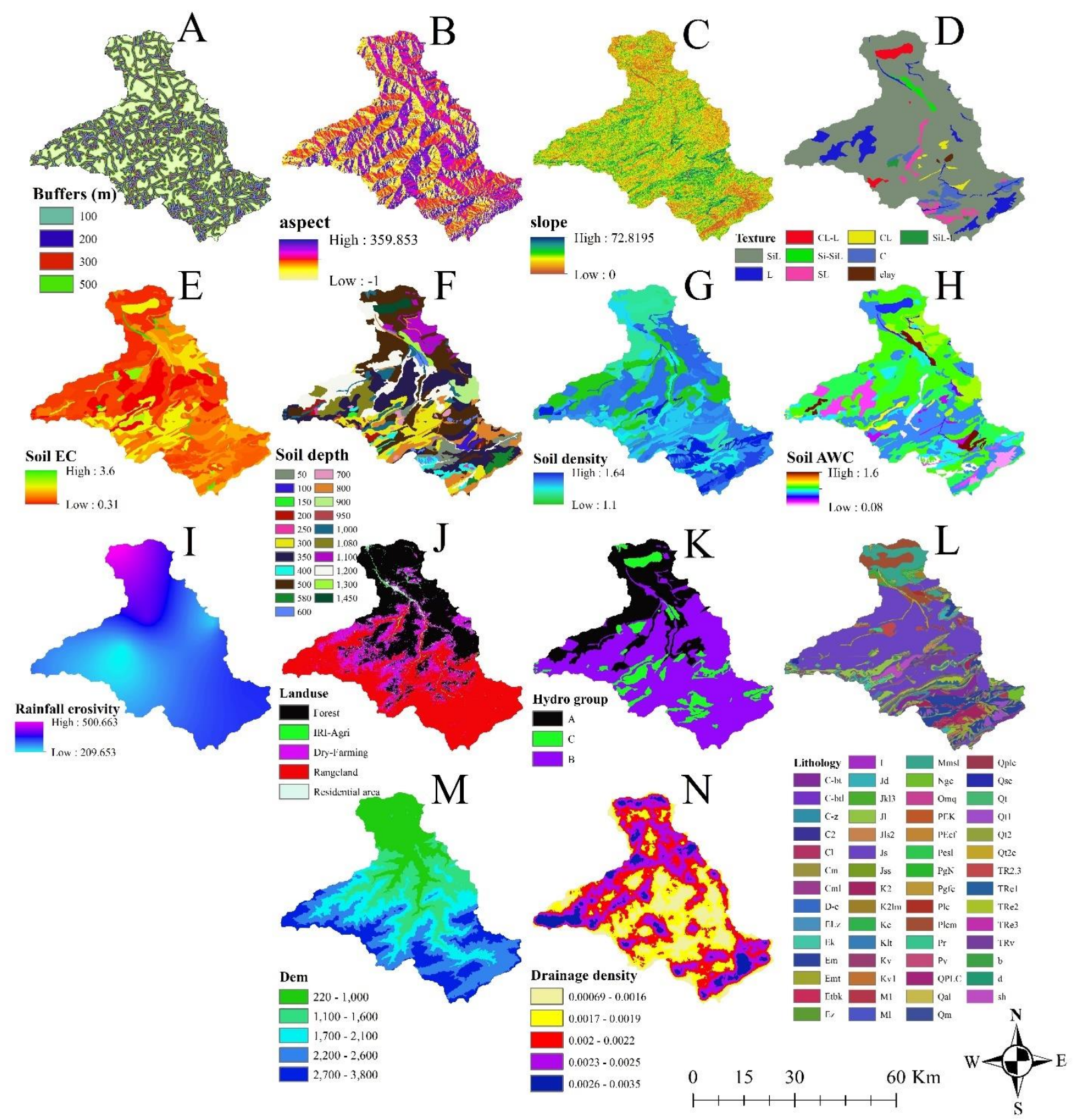

Fig. 4 The distribution of variables that influence soil erosion in Talar Watershed - A: river buffer, B: erosivity, J: land use, K: hydrological group, L: lithology M: elevation, N: drainage density. 


\subsubsection{RUSLE model}

167 The RUSLE model shows how rills are affected by soils, climate, topography, and land use.

168 Raindrop impacts and surface runoff cause inter-rill soil erosion (Renard et al. 1991). This equation 169 is a function of five factors that were mapped as rasters: slope length and gradient, rainfall 170 erosivity, soil erodibility, land cover and vegetation management, and land use practices. These 171 parameters vary in time and space and depend on other variables. The average annual soil loss $(A)$ 172 (ton/hectare/year) at any location can be estimated using RUSLE (Eq. 1) (Renard et al. 1991): 173

$$
A=R \times K \times L S \times C \times P
$$

174

175 where $R$ is rainfall erosivity (MJ/hectare/mm); $K$ is the soil erodibility (ton/hectare/year); $L S$ is the 176 slope length and slope gradient (dimensionless); $C$ is the cover management practice 177 (dimensionless); and $P$ is the conservation support or erosion control practices (dimensionless). 178 Wischmeier and Smith's equation was used to calculate the soil erodibility factor (Eq.2) 179 (Wischmeier 1976):

180

$$
100 K=2.1 M^{1.14} \times 10^{-4} \times(12-\% O M)+3.25(S-2)+2.5(P-3)
$$

182 where $K$ is the soil erodibility, $M$ is particle size (\% silt + \%very fine sand) * (100 - \% clay), OM 183 is the organic matter content (\%), and $S$ and $P$ are the soil structure and permeability classes, 184 respectively. The number of meteorological stations in the study area is low. Therefore, to increase 185 accuracy, rainfall gauges located outside the watershed but near the watershed boundaries were 
186

187

188

$$
\begin{aligned}
& R=0.7397 F^{1.847}, F<5 \mathrm{~mm} \\
& R=95.77-6.081 F+0.477 F^{2}, F>55 \mathrm{~mm} \\
& F=\sum_{i=1}^{12} P_{i}^{2} / \bar{P}
\end{aligned}
$$

189

190

191

192 (normalized different vegetation index) (De Jong 1994, Lin et al. 2002, Wang et al. 2002). The

193 vegetation cover was determined from Landsat satellite images from the USGS website 194 (https://earthexplorer.usgs.gov/). Vegetation cover maps were created using supervised 195 classification of imagery based on the maximum likelihood algorithm in the ENVI 5.1 by applying 196 overall accuracy and the $\kappa$ coefficient to determine classification accuracy. NDVI is derived from 197 the red and near-infrared bands using the following (Eq. 6) (Zhang et al. 2010):

198

$$
N D V I=\left(\rho_{N I R}-\rho_{\text {Red }}\right) /\left(\rho_{N I R}+\rho_{\text {Red }}\right)
$$

200 where $\rho_{\text {Red }}$ and $\rho_{\text {NIR }}$ are the spectral reflectance of the red and near-infrared bands in each pixel of 201 the image. $C$ was obtained for each pixel with (Eq. 7):

202

$$
\text { C Factor }=0.407-0.5953 \times N D V I
$$


$L S$ incorporates gradient, slope length and shape to determine sediment yield (Pradhan et al. 2012). A program written in Arc Macro Language was acquired from http://www.iamg.org and was used to calculate $L S$ (Hickey 2000). It was updated in 2004 with $\mathrm{C}++$ programming language. The program automatically processes DEM data to calculate $L S$ (Van Remortel et al. 2004). A value for $P$ was determined for each land use (Troeh et al., 1980). A map of soil erosion in the Talar watershed was produced by integrating the distribution of the five RUSLE factors and then reclassifying their product into three erosion classes of low, moderate, and high (Fig. 5).

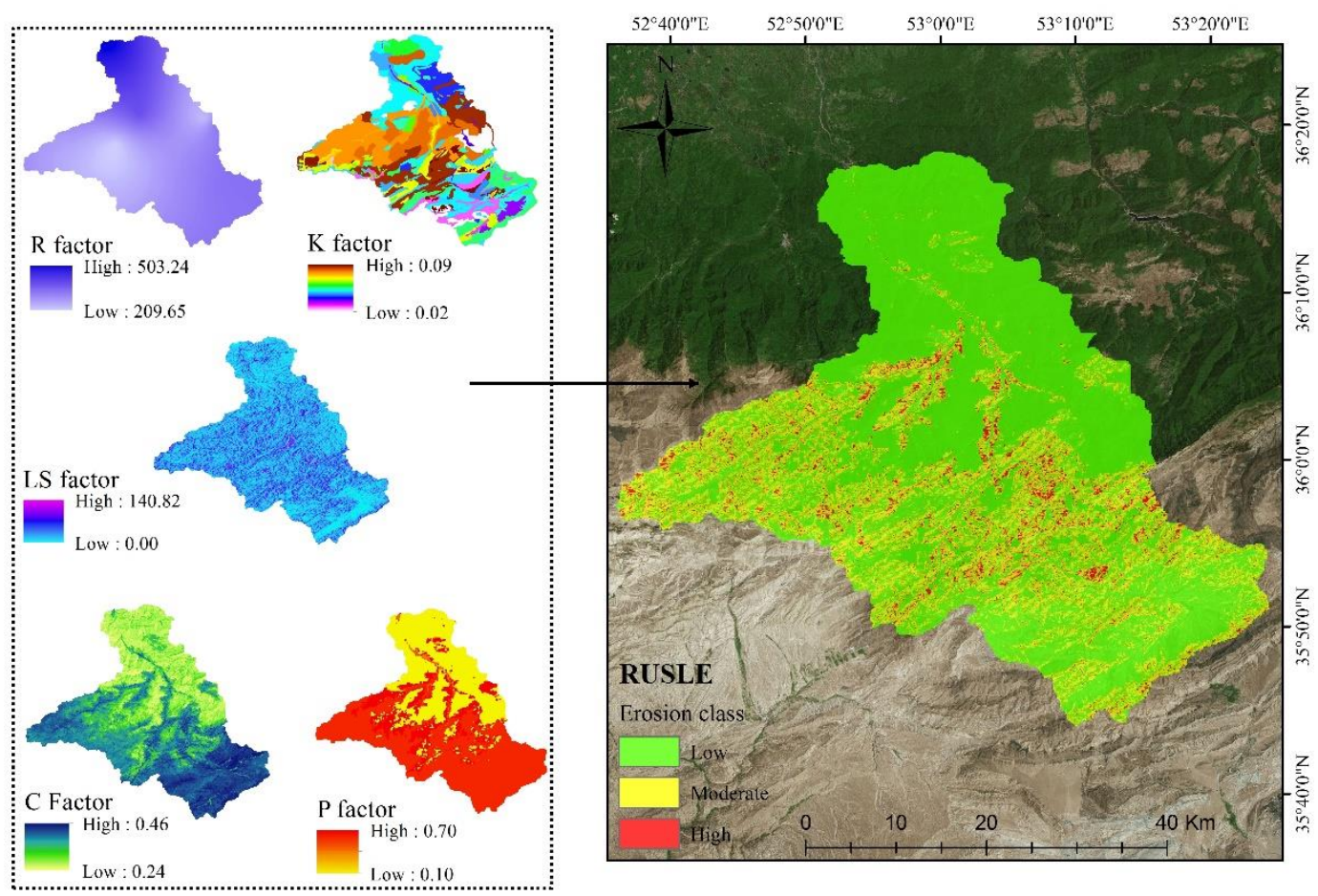

Fig. 5 The RUSLE factors and erosion classes 
$216 \mathrm{RF}$ is a popular ML algorithm that is used for both classification and regression. This model

217 includes decision tree that are used for determine the relationships between soil erosion intensity 218 and the contributing conditioning factors. RF combines numerous trees. It handles random trees 219 that implement subsets of the observations by bootstrapping. A random selection of training data 220 is used to create a model, and the data that are not used to calibrate k-trees in the bagging process 221 are regarded as out-of-bag (OOB) data. To use RF, it is necessary to define two parameters: the 222 number of factors to be used in each tree-building process (mtry) and the number of trees to be 223 built in the forest (ntree). RF can determine the importance of each conditioning factor based on 224 the amount of increase in the error of prediction as the OBB for the factor are permuted while all 225 others remain fixed (Naghibi et al. 2017). The RF modelling was performed using the "Random 226 Forest" package of R. The output map was input into ArcGIS to create the soil-erosion map of the 227 Talar watershed.

\subsubsection{Application of artificial neural network (ANN)}

230 The design of ANNs is inspired by a biological neural system. They mimic human brain 231 performance. Generally, ANNs consist of interconnected processing elements (PEs) called nodes.

232 These nodes are organized into three or more layers that include an input layer, one or more hidden 233 layers, and an output layer. The number of neurons in the input and output layers depends on the 234 problem, and the number of neurons in hidden layers are determined through trial and error, a 235 process that is fixed for the particular application (Isazadeh et al. 2017). Many types of 236 architectures, like the multilayer feed-forward and back-propagation algorithms, have been 237 proposed. In this study, ANN was structured on a multilayer-perceptron architecture and the back- 
238 propagation algorithm for the training. The number of hidden layers in the ANN was set at 5 and 239 the learning rate of the model was set at 9.

\subsubsection{Application of generalized linear model (GLM)}

242 GLM statistical models are increasingly used to study the relationships between dependent and 243 independent variables. GLMs can be used with categorical and continuous data, or a combination 244 thereof (Atkinson et al. 1998). This model does not force data into unnatural scales. The data can 245 be linear, non-linear, or have non-constant variance structures (Mirchooli et al. 2019). The 246 relationships between combinations of predictors and the mean of the response variable is 247 represented as a link function. GLMs can be based on Poisson, Binomial, Gaussian, or Gamma 248 distributions. The general form of this model is:

$249 l=a+b_{1} x_{1}+b_{2} x_{2}+\cdots+b_{k} x_{k}$

250 where 1 is the linear predictor and is related to the expectation, $\mathrm{u}$. The link function form is:

$251 \quad g(u)=l$

252

\subsubsection{Application of classification-tree analysis (CTA)}

254 CTA is a rule-based process that generates a binary tree by dividing a node into yes or no predictor 255 values. It is called the binary recursive partitioning process. Each node is based on a single factor, 256 and the rule generated at each step minimizes the variability within each resulting subset, splitting 257 them further based on each relationship. The result of CTA is a hierarchical binary tree. The 258 response to each factor is premised on the values of prior inputs higher in the tree so that the 259 relationships and interactions between factors will be modelled automatically. This model is easy 260 and straight forward to interpret. It produces results that are intuitive and easy to visualize. 


\subsection{Model Calibration and Validation}

263 The $30 \%$ of the soil-erosion hot spots that were not employed in the modeling process, were used 264 to validate the results of these models (Rahmati et al. 2016). The accuracies of the models were 265 determined using the receiver operating characteristic (ROC) curve and associated area under the 266 curve (AUC). ROC indicates how well a model predicts an outcome (i.e., soil erosion). It is widely 267 used to measure performance. ROC ranges from 0 to 1 , but values below 0.5 indicate the model is 268 random and not meaningful, but values above 0.5 indicate the model has some predictive value 269 (Pourghasemi et al. 2013).

\section{Results}

\section{3.1. Multi-collinearity analysis}

272 The variance inflation factor (VIF) and tolerance (TOL) analyses were used to eliminate factors 273 are high correlated to others. Highly correlated variables will have very similar effects on soil

274 erosion, so removal can improve the accuracies of predictive models. The threshold value of VIF

275 for removal is 5. The analysis revealed that all factors except curvature (VIF=5.43) and TPI 276 (VIF=6.47) had VIF values below 5. Curvature and TPI were removed from the modeling process 277 (Table 3).

Table 3. Multi-collinearity analysis between the factors used

\begin{tabular}{cccc}
\hline Number & Variables & VIF $(\mathrm{th} \leq 5)$ & TOL \\
\hline 1 & Aspect & 1.13 & 0.88 \\
2 & Drainage density & 1.20 & 0.83 \\
3 & Elevation & 2.83 & 0.35 \\
4 & Distance to river & 1.35 & 0.74 \\
5 & Geology & 1.29 & 0.77 \\
6 & Hydro-group & 2.30 & 0.43 \\
7 & Land use & 1.84 & 0.54 \\
\hline
\end{tabular}




\begin{tabular}{cccc}
\hline 8 & Rainfall erosivity & 1.88 & 0.53 \\
9 & Slope & 1.05 & 0.95 \\
10 & Soil AWC & 1.10 & 0.90 \\
11 & Soil EC & 1.16 & 0.86 \\
12 & Soil density & 1.55 & 0.64 \\
13 & Soil depth & 1.67 & 0.59 \\
14 & Soil texture & 1.12 & 0.89 \\
15 & Curvature & 5.43 & 0.18 \\
16 & TPI & 6.47 & 0.15 \\
\hline
\end{tabular}

279

\subsection{Importance factors analysis}

281 The relative importance of the conditioning factors in the RF, ANN, GLM, and CTA models was

282 determined (Fig. 6). Slope angle, land use/land cover, elevation, and rainfall erosivity are the most

283 important soil erosion conditioning factors in all four models of the Talar watershed. These factors

284 are also reflected in the previous spatial analysis of soil erosion events (i.e., observations) (Fig. 3)

285 which demonstrated that there were locations where several factors contributed to soil erosion.

286 However, there were significant differences in the contribution of soil erosion factors among the

287 assorted models.

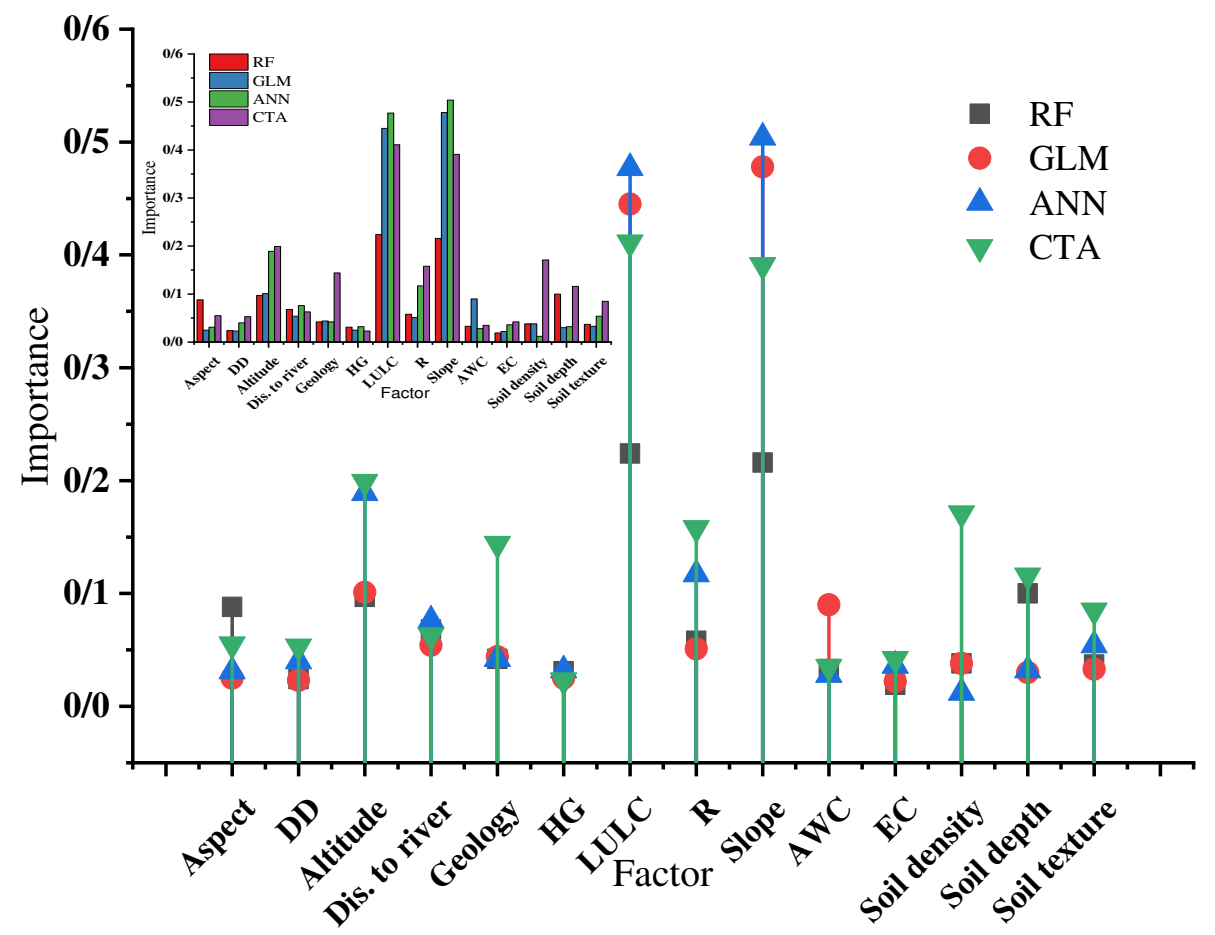


Fig. 6 Importance soil erosion factors affecting

290

291

\subsection{Spatial Prediction of Water Erosion Susceptibility}

292 To better visualize and prioritize areas of erosion, the classes of the models' predictions were 293 mapped and classified as very low, low, moderate, high and very high (Fig. 7). These were divided 294 using the natural break algorithm in Arc Map software (Talukdar et al. 2020, Yousefi et al. 2020). 295 Soil erosion susceptibility is an estimation of risk that an area experiences erosion in any future 296 year. In these maps, red indicates areas with very high potential for soil erosion and gray indicates 297 that, comparatively, there is very low potential for soil erosion (though all of these zones would 298 likely generate more than 16 tons/ha/yr. In all four maps, it can be seen that the highest potential 299 for erosion is found in upstream and middle portions of the watershed. There is, however, a 300 significant difference between the proportions of the watershed classified at particular levels of 301 susceptibility by the four models. 


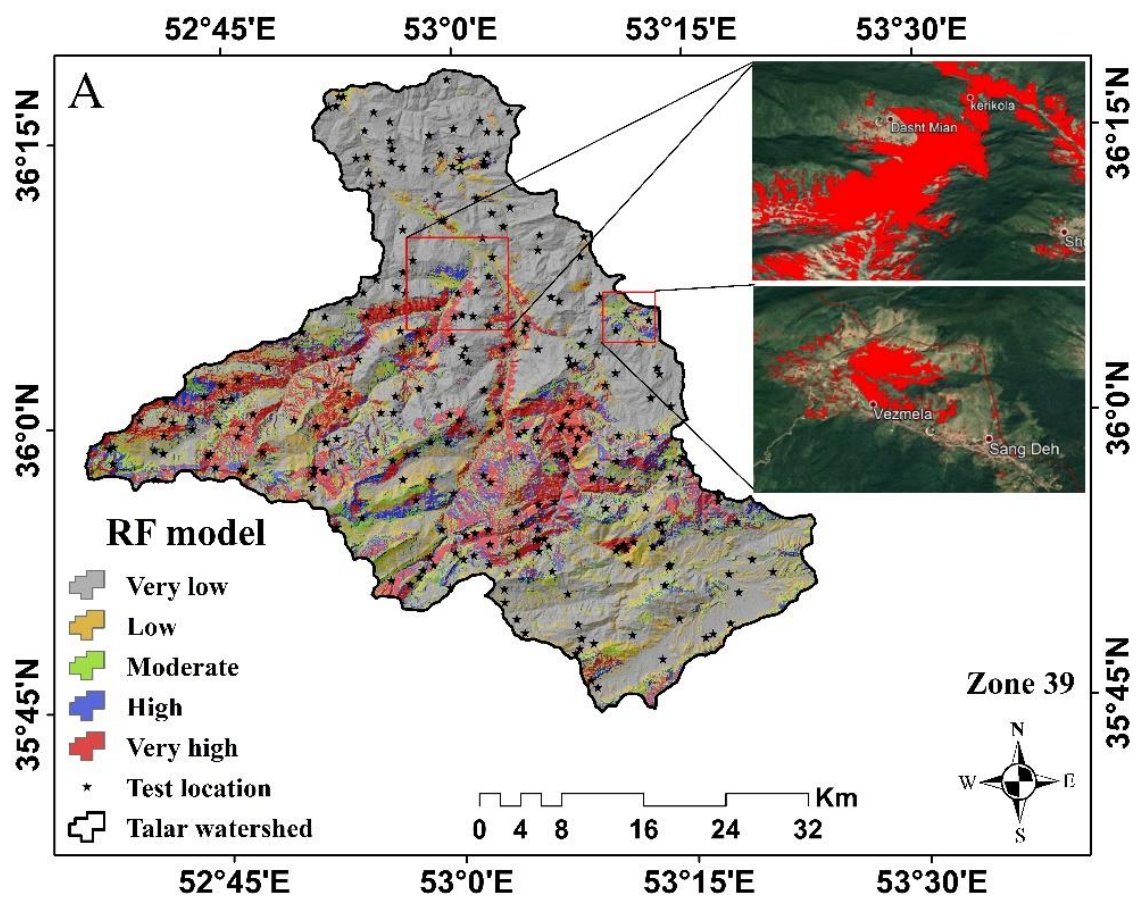

305

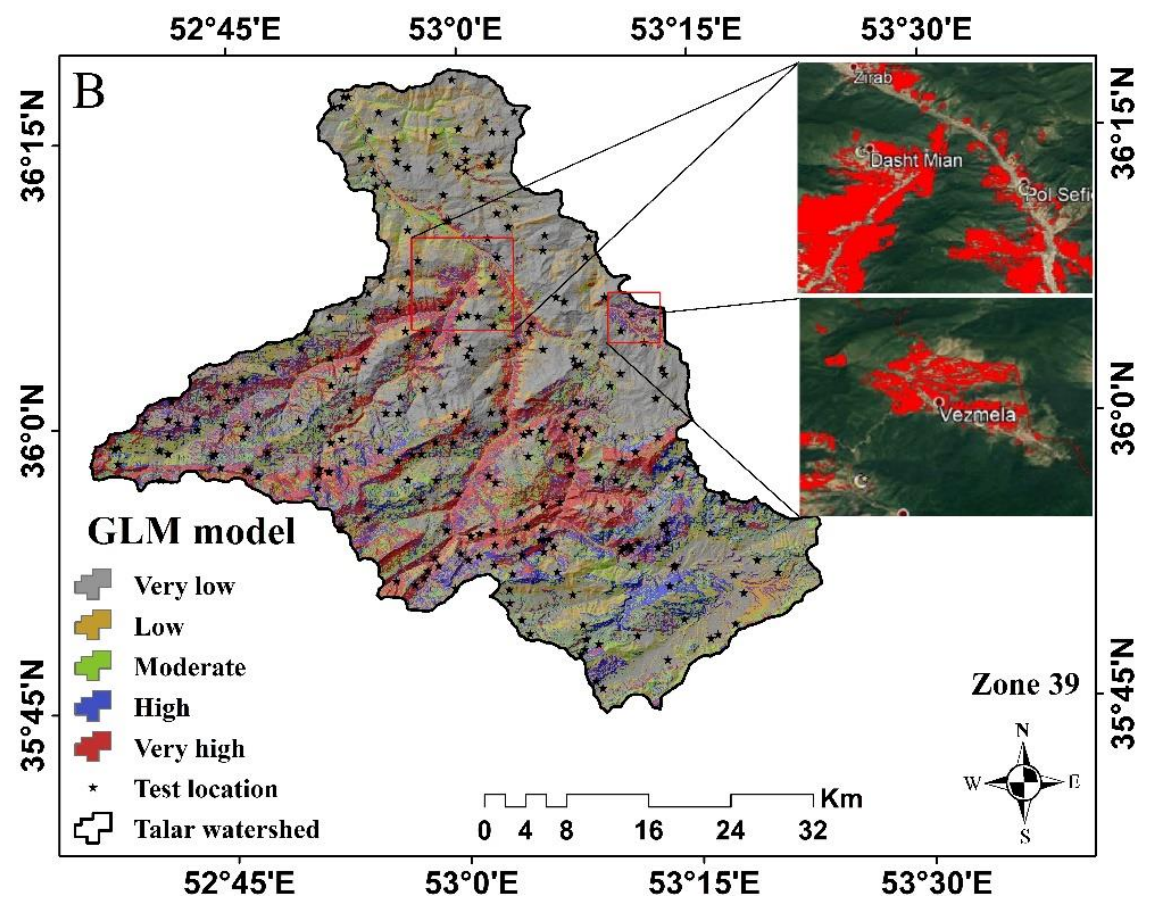



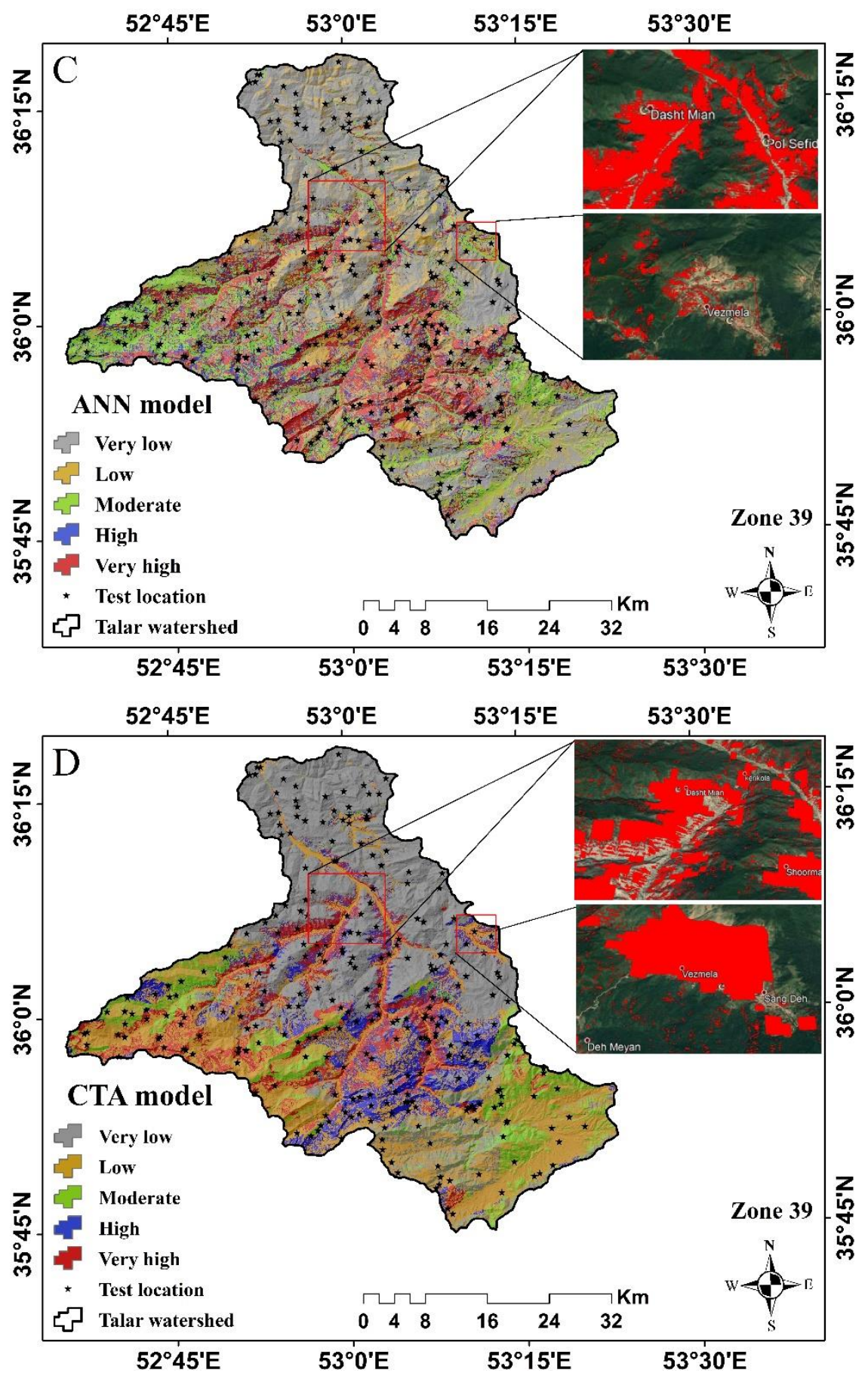

309 Fig. 7 Predictions of soil erosion susceptibility using the four models: A: RF; B: GLM; C: ANN; D: CTA

311 The proportions of the watershed classified into the five soil-erosion susceptibility classes (very 312 low, low, moderate, high, and very high) were determined for each of the four methods (Fig. 8).

313 The RF model predicted $32 \%$ of the study area has very low susceptibility, $16 \%$ has low 
314 susceptibility, $18 \%$ moderate, $22 \%$ high, and $24 \%$ very high. The ANN predicted $22 \%$ very low,

$31520 \%$ low, $39 \%$ moderate, $20 \%$ high, and 32\% very high. GLM predicted $23 \%$ very low, $21 \%$ low,

$31626 \%$ moderate, $35 \%$ high, $28 \%$ very high. And CTA predicted $23 \%$ very low, $43 \%$ low, $16 \%$

317 moderate, $23 \%$ high, and $16 \%$ very high. In comparison, ANN predicted $32 \%$ of the area was very

318 highly susceptible, GLM predicted 28\%, CTA predicted 24\%, and RF only $16 \%$. All five classes

319 produce more than 16 tons of erosion per ha per year; more erosion than allowed in Iran and the

320 world, so all of these classes are of concern, but very high erosion rates are significantly bad.

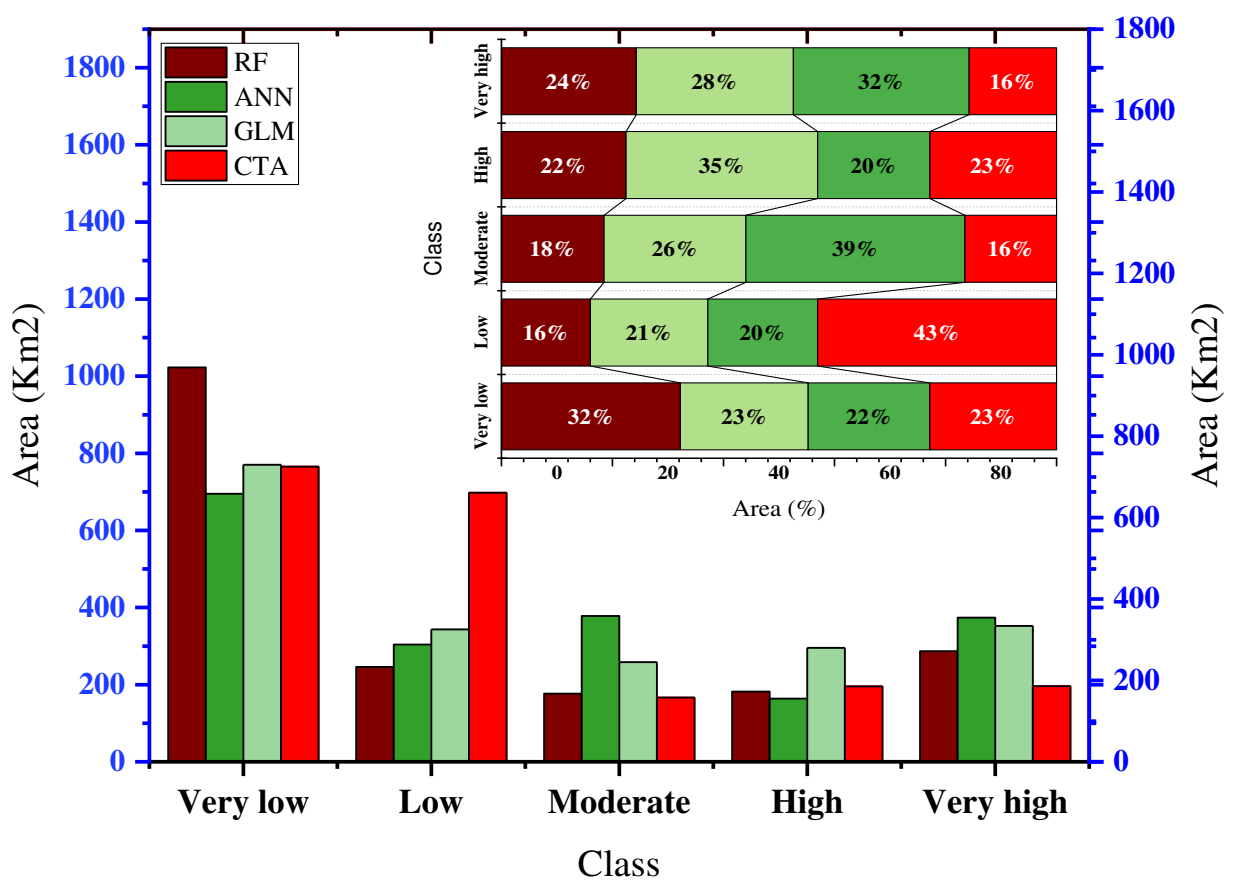

322

Fig. 8 Area of the soil erosion classes found using each model 


\subsection{Assessment of soil erosion risk zone and management strategies}

327 The predictive performances (i.e., accuracies assessed in the validation step) of the four models 328 were determined based on AUC values (Fig. 9). To objectively evaluate the predictive capabilities 329 of these models, we also reviewed recent ML extreme-event studies (i.e., floods, landslides, and 330 erosion) (Avand et al. 2020, Pham et al. 2020, Yariyan et al. 2020). The RF model had the highest 331 accuracy $($ AUC $=0.973)$. This was followed by the ANN $(A U C=0.90)$, GLM $(A U C=0.894)$ and

332 CTA $(\mathrm{AUC}=0.866)$ models. Also, the binary comparison diagram of the models using the two 333 criteria of sensitivity and precision is shown in Figure 10.

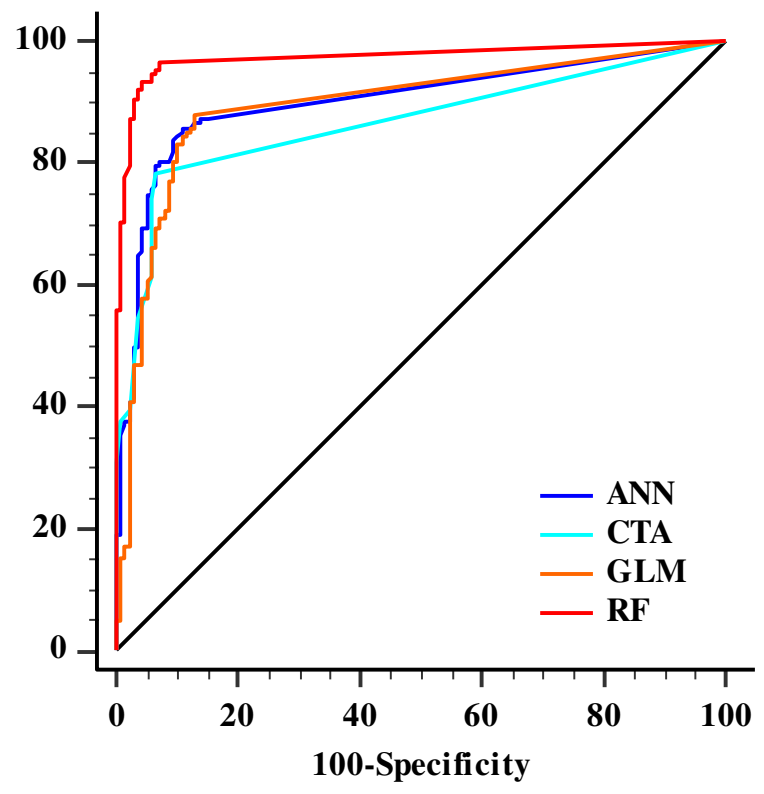

Fig. 9 ROC curves for all the methods using validation dataset. 

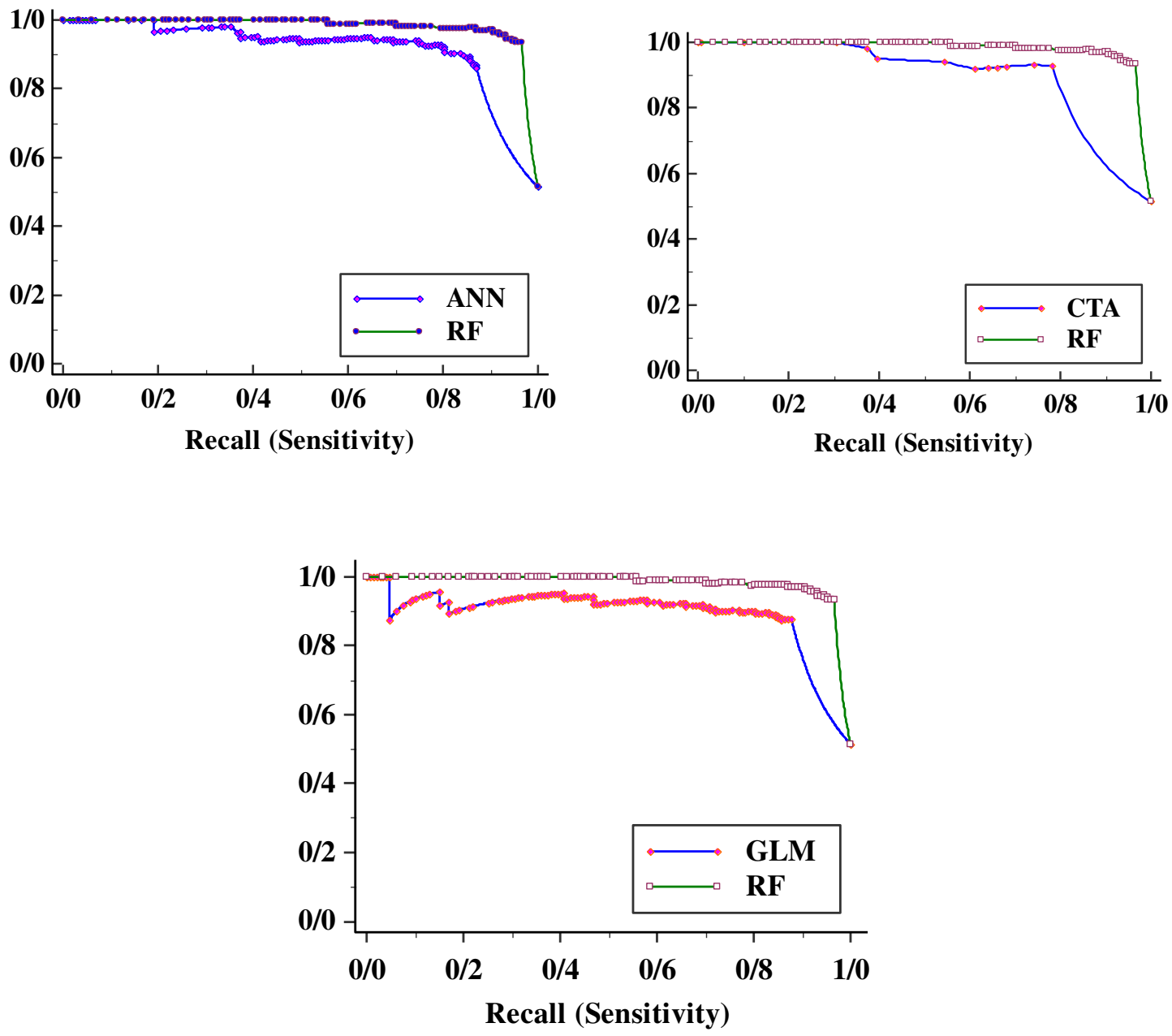

Fig. 10 Sensitivity analysis of GLM, ANN and CTA models compared to the RF model

341 RF had superior performance by all metrics: $\mathrm{SE}=0.008$, Accuracy $=0.92$, Sensitivity $=0.966$,

342 Specificity $=0.928$, and Kappa $=0.78$. ANN was second best: $\mathrm{SE}=0.018$, Accuracy $=0.84$,

343 Sensitivity $=0.851$, Specificity $=0.893$, and Kappa $=0.68$. GLM ranked third: $\mathrm{SE}=0.019$,

344 Accuracy $=0.878$, Sensitivity $=0.871$, Specificity $=0.835$, and Kappa $=0.64$. And the CTA was

345 weakest: $\mathrm{SE}=0.019$, Accuracy $=0.77$, Sensitivity $=0.782$, Specificity $=0.935$, and Kappa $=62$

346 (Table 4). 
Table 4. The performances of the models using the testing dataset.

\begin{tabular}{|c|c|c|c|c|c|c|c|c|c|}
\hline Griteria & AUC & SE & $95 \% \mathrm{CI}$ & Accuracy & Sensitivity & Specificity & TSS & Bias & Kappa \\
\hline RF & 0.973 & 0.008 & $\begin{array}{c}0.94 \text { to } \\
0.98\end{array}$ & 0.93 & 0.966 & 0.928 & 0.73 & 0.92 & 0.78 \\
\hline GLM & 0.894 & 0.019 & $\begin{array}{c}0.85 \text { to } \\
0.92\end{array}$ & 0.878 & 0.871 & 0.835 & 0.62 & 0.95 & 0.64 \\
\hline ANN & 0.90 & 0.018 & $\begin{array}{c}0.86 \text { to } \\
0.93\end{array}$ & 0.84 & 0.851 & 0.893 & 0.65 & 0.94 & 0.68 \\
\hline CTA & 0.866 & 0.019 & $\begin{array}{c}0.82 \text { to } \\
0.93\end{array}$ & 0.77 & 0.782 & 0.935 & 0.61 & 0.92 & 0.62 \\
\hline
\end{tabular}

348

349

350

351

352

353

354

355

356

357

358

359

360

361

362

\section{Discussion}

Identification of hot spots of soil erosion can help to identify ways to reduce erosion. This study integrated RUSLE with four ML models - RF, ANN, GLM and CTA - to predict the areas in the Talar watershed of Mazandaran Province, Iran, with the greatest potential for soil erosion. To operationalize this research, data for 14 independent variables believed to contribute to soil erosion were compiled. The ML models were trained and validated with 488 soil erosion locations (locations with observed soil erosion). These points were extracted from the RUSLE output map and were randomly separated into two groups for training $(70 \%=342)$ and validation $(30 \%=$ 146). A multicollinearity analysis indicated that profile curvature and TPI were highly correlated with elevation and slope, respectively, and were removed. All other factors were independent of each other. Therefore, 12 independent factors were used in the model training and validation processes.

\section{Driving factors of soil erosion}

Analysis of the twelve factors' contributions to erosion showed that four - slope, land use, elevation, and rain erosivity were the most important. A large portion of the Talar watershed is 
mountainous, especially the southern part of the watershed. Decreasing soil depth, diminishing vegetation, and increasing slope angle in mountains accelerates erosion (Mohammadi et al. 2017). Slope is usually the factor deemed most important promoter of soil erosion in most studies (Arekhi et al. 2012, Samanta et al. 2016, Lei et al. 2020). Slope angle changes erosion rates by influencing runoff velocity, the abundance of vegetation, and soil type. Slopes greater than 30 degrees, though having increased erosion potential from faster moving water and less vegetation, eventually become rocky with erosion-resistant formations and erosion is reduced due to lack of soil. Increasing the slope length, also increases erosion rates due to flow conditions (flow velocity, volume, and shear stress). These findings are consistent with studies by Atoma et al. (2020) and Tadesse and Tefera (2020).

As slopes decrease in flatter topography, different soil types will form, and vegetation will usually provide more dense cover and protection from the impact of rainfall. Rain intensity and the kinetic energy of raindrops greatly affect soil erosion potential. Changing climates in Iran, particularly in areas experiencing increased precipitation rates in the northern portions of the country, have prompted greater soil erosion in many watersheds as discussed in Kavian et al. (2011) and Sadeghi et al. (2017).

The type and severity of erosion depends upon land use as well. Subsurface water flow in forested areas can produce gully erosion. Forests in the Talar watershed influence soil erosion on steep slopes and produce debris that can augment mass wasting. Agricultural tillage enables greater infiltration into soil and can cause mass erosion. The use of machinery and frequent plowing affects surface runoff and erosion rates by changing the physical properties of the soils. Such mechanisms for soil erosion in agricultural lands have been discussed (Silva et al. 2009, Filoso et al. 2015). 
388 And rill erosion is more prevalent in rangelands (Vaezi and Sadeghi 2011, Zare et al. 2017).

389 Deforestation, mining, and the development of residential land uses and roads has also intensified

390 erosion in this region.

391 To understand the patterns of soil erosion susceptibility in the landscapes of the Talar watershed, 392 the ML models' predictions were mapped and classified using the natural break method in 393 ArcMap. The classifications were summed, and a proportion of the watershed area covered by 394 each of the 5 classes (very low to very high) were calculated for each of the four ML models. All 395 five classes had erosion rates above the original base rate of 16 ton/ha/yr. The results reveal some 396 variation in the areal extents of the classes produced by each model, but the visual pattern indicates 397 that the regions of high and very high susceptibility are near stream paths and in upstream areas of 398 steep slopes, areas that typically have little to no vegetation.

\section{Performance of MLMs on hot spot soil erosion mapping}

$400 \mathrm{RF}$ is the ML modeling approach that produced the greatest prediction power. Ranking next was 401 ANN, then GLM, and CTA. An advantage of the RF model is that it employs the best randomly 402 selected variables (or dividing points) in sub-groups to produce a growth tree and in so doing it 403 reduces the strength of each individual regression tree. This reduction in the matching rate reduces 404 model error (Breiman 2001). To improve the learning of classification machines and regression 405 models and to reduce variance and prevent overfitting, a complex RF model is used (Immitzer et 406 al. 2012, Breiman 2017), which is consistent with Towfiqul Islam et al. (2020) and Chen et al. 407 (2020) who state that the RF is very accurate when predicting extreme events (like floods, erosion, 408 landslides, et al.). 
409 Soil erosion and sediment deposition, especially in agricultural lands, lead to soil loss, reduced soil

410 depth, soil structure decomposition, reduced fertility, and reduced organic matter and nutrients.

411 These losses may lead to abandonment. ML models can help decision makers identify areas with

412 high erosion potential and can focus management efforts. Based on the results of this study,

413 RUSLE in combination with RF could be used by natural resource managers to guide zoning of

414 land use practices and to identify hot spots of soil-erosion susceptibility in regions similar to the

415 Talar watershed.

416

417 Author Declarations

$418 \quad$ Funding

419 This research received no specific grant from any funding agency in the public, commercial, or 420 not-for-profit sectors.

421 Conflicts of interest

422 The authors declare that they have no known competing financial interests or personal 423 relationships that could have appeared to influence the work reported in this paper.

424 Availability of data and material

425 Data not available due to [ethical/legal/commercial] restrictions.

426 Code availability

427 Not applicable

428 Authors' contributions

429 Data curation, M.A and M.M; formal analysis, M.A and M.M; funding acquisition, M.A and 430 A.K; investigation, M.A and M.M; methodology, A.K., M.A., and M.M; supervision, M.A;

431 validation, F.M and M.M; visualization, M.A, M.M, and F.M; writing — original draft, M.A. 
432 and M.M.; writing - review and editing, J.P.T., and A.K; All authors have read and agreed to

433 the published version of the manuscript.

\section{References}

Ali, G., C. Birkel, D. Tetzlaff, C. Soulsby, J. J. McDonnell, and P. Tarolli. 2014. A comparison of

Amine, M., E. Maaoui, M. Sfar, M. Rached, and M. Habib. 2012. Catena Sediment yield from irregularly shaped gullies located on the Fortuna lithologic formation in semi-arid area of Tunisia. Catena 93

Arekhi, S., A. Darvishi, A. Shabani, H. Fathizad, and S. Ahmadai Abchin. 2012. Mapping soil erosion

Avand, M., H. Moradi, and M. Ramazanzadeh. 2020. Using machine learning models , remote sensing ,

Atoma, H., K. V. Suryabhagavan, and M. Balakrishnan. 2020. Soil erosion assessment using RUSLE model and GIS in Huluka watershed, Central Ethiopia. Sustainable Water Resources Management $6(1): 1-17$. Gardalan Watershed, Iran). J. Adv. Environ. Biol 6(1):109-124. and GIS to investigate the effects of changing climates and land uses on flood probability. Journal of Hydrology(October):125663.

Bagio, B., I. Bertol, N. H. Wolschick, D. Schneiders, and M. A. do N. dos Santos. 2017. Water Erosion in Different Slope Lengths on Bare Soil. Revista Brasileira de Ciência do Solo 41 (2017).

453 Bouchnak, H., M. S. Felfoul, M. R. Boussema, and M. H. Snane. 2009. Slope and rainfall effects on the volume of sediment yield by gully erosion in the Souar lithologic formation (Tunisia). Catena 
Breiman, L. 2001. Random forests. Machine Learning 45(1):5-32.

Breiman, L. 2017. Classification and regression trees. Routledge.

458

Chalise, D., L. Kumar, V. Spalevic, and G. Skataric. 2019. Estimation of sediment yield and maximum outflow using the IntErO model in the Sarada River Basin of Nepal. Water (Switzerland) 11(5).

Chen, W., Y. Li, W. Xue, H. Shahabi, S. Li, H. Hong, X. Wang, H. Bian, S. Zhang, B. Pradhan, and B. Bin Ahmad. 2020. Modeling flood susceptibility using data-driven approaches of naïve Bayes tree, alternating decision tree, and random forest methods. Science of the Total Environment 701 (January 2020):134979.

Engineering Services Company. 2002. Comprehensive study: Talar watershed. Mazandaran.

Faulkner, H. 2013. Badlands in marl lithologies: a field guide to soil dispersion, subsurface erosion and piping-origin gullies. Catena 106 (2013):42-53.

Filoso, S., J. B. do Carmo, S. F. Mardegan, S. R. M. Lins, T. F. Gomes, and L. A. Martinelli. 2015. Reassessing the environmental impacts of sugarcane ethanol production in Brazil to help meet sustainability goals. Renewable and Sustainable Energy Reviews 52 (2015):1847-1856.

Gayen, A., H. Reza, S. Saha, S. Keesstra, and S. Bai. 2019. Science of the Total Environment Gully erosion susceptibility assessment and management of hazard- prone areas in India using different machine learning algorithms. Science of the Total Environment 668 (2019):124-138.

Hickey, R. 2000. Slope angle and slope length solutions for GIS. Cartography 29(1):1-8.

Immitzer, M., C. Atzberger, and T. Koukal. 2012. Tree species classification with Random forest using very high spatial resolution 8-band worldView-2 satellite data. Remote Sensing 4(9):2661-2693.

Isazadeh, M., S. M. Biazar, and A. Ashrafzadeh. 2017. Support vector machines and feed-forward neural 
networks for spatial modeling of groundwater qualitative parameters. Environmental Earth Sciences 76(17):1-14.

479 480

481

482

483

484 485 486

487 488

De Jong, S. M. 1994. Application of Reflective Remote Sensing for Land Degradation Studies in a Mediterranean Environment (Utrecht: Netherlands Geographical Studies, University of Utrecht) (1994).

Karamidehkordi, E. 2010. A country report: Challenges facing Iranian agriculture and natural resource management in the twenty-first century. Human Ecology 38(2):295-303.

Kavian, A., Y. Fathollah Nejad, M. Habibnejad, and K. Soleimani. 2011. Modeling seasonal rainfall erosivity on a regional scale: a case study from Northeastern Iran. International Journal of Environmental Research 5(4):939-950.

Koirala, P., S. Thakuri, S. Joshi, and R. Chauhan. 2019. Estimation of Soil Erosion in Nepal Using a RUSLE Modeling and Geospatial Tool (2019).

Lei, X., W. Chen, M. Avand, S. Janizadeh, N. Kariminejad, H. Shahabi, R. Costache, H. Shahabi, A. Shirzadi, and A. Mosavi. 2020. GIS-based machine learning algorithms for gully erosion susceptibility mapping in a semi-arid region of Iran. Remote Sensing 12(15):2478.

Lin, C.-Y., W.-T. Lin, and W.-C. Chou. 2002. Soil erosion prediction and sediment yield estimation: the Taiwan experience. Soil and Tillage Research 68(2):143-152.

Mirchooli, F., A. Motevalli, H. R. Pourghasemi, M. Mohammadi, P. Bhattacharya, F. F. Maghsood, and J. P. Tiefenbacher. 2019. How do data-mining models consider arsenic contamination in sediments and variables importance? Environmental Monitoring and Assessment 191(12).

Mohammadi, M., H. Darabi, F. Mirchooli, A. Bakhshaee, and A. Torabi Haghighi. 2020. Flood risk mapping and crop-water loss modeling using water footprint analysis in agricultural watershed, northern Iran. Natural Hazards(0123456789). 
MOHAMMADI, M., M. FALLAH, A. KAVIAN, L. GHOLAMI, and E. OMIDVAR. 2017. The Application of RUSLE Model in Spatial DistributionDetermination of Soil loss Hazard (2017).

Mohammed, S., K. Alsafadi, S. Talukdar, S. Kiwan, S. Hennawi, O. Alshihabi, M. Sharaf, and E. Harsanyie. 2020. Estimation of soil erosion risk in southern part of Syria by using RUSLE integrating geo informatics approach. Remote Sensing Applications: Society and Environment 20(July):100375.

Mousavi, S. M., A. Golkarian, S. A. Naghibi, B. Kalantar, and B. Pradhan. 2017. GIS-based Groundwater Spring Potential Mapping Using Data Mining Boosted Regression Tree and Probabilistic Frequency Ratio Models in Iran. AIMS Geosciences 3(1):91-115.

Mukherjee, S., P. K. Joshi, S. Mukherjee, A. Ghosh, R. D. Garg, and A. Mukhopadhyay. 2013. Evaluation of vertical accuracy of open source Digital Elevation Model (DEM). International Journal of Applied Earth Observation and Geoinformation 21 (2013):205-217.

Naghibi, S. A., K. Ahmadi, and A. Daneshi. 2017. Application of Support Vector Machine, Random Forest, and Genetic Algorithm Optimized Random Forest Models in Groundwater Potential Mapping. Water Resources Management 31(9):2761-2775.

Nyesheja, E. M., X. Chen, A. M. El-Tantawi, F. Karamage, C. Mupenzi, and J. B. Nsengiyumva. 2019. Soil erosion assessment using RUSLE model in the Congo Nile Ridge region of Rwanda. Physical Geography 40(4):339-360.

Pham, B. T., T. Van Phong, M. Avand, N. Al-Ansari, S. K. Singh, H. Van Le, and I. Prakash. 2020. Improving Voting Feature Intervals for Spatial Prediction of Landslides. Mathematical Problems in Engineering 2020 (2020).

Pham, T. G., J. Degener, and M. Kappas. 2018. Integrated universal soil loss equation (USLE) and Geographical Information System (GIS) for soil erosion estimation in A Sap basin: Central 
Vietnam. International Soil and Water Conservation Research 6(2):99-110.

524 Phinzi, K., N. S. Ngetar, and O. Ebhuoma. 2020. Soil erosion risk assessment in the Umzintlava

525 catchment (T32E), Eastern Cape, South Africa, using RUSLE and random forest algorithm. South

526 African Geographical Journal 00(00):1-24.

527 Pourghasemi, H. R., A. G. Jirandeh, B. Pradhan, C. Xu, and C. Gokceoglu. 2013. Landslide susceptibility 528 mapping using support vector machine and GIS at the Golestan Province, Iran. J. Earth Syst. Sci. 529 Indian Academy of Sciences 122(2):349-369.

530 Pourghasemi, H. R., H. R. Moradi, S. M. Fatemi Aghda, C. Gokceoglu, and B. Pradhan. 2014. GIS-based 531 landslide susceptibility mapping with probabilistic likelihood ratio and spatial multi-criteria 532 evaluation models (North of Tehran, Iran). Arabian Journal of Geosciences 7(5):1857-1878.

533 Pournader, M., H. Ahmadi, S. Feiznia, H. Karimi, and H. R. Peirovan. 2018. Spatial prediction of soil 534 erosion susceptibility: an evaluation of the maximum entropy model. Earth Science Informatics $535 \quad 11(3): 389-401$.

536 Pradhan, B., A. Chaudhari, J. Adinarayana, and M. F. Buchroithner. 2012. Soil erosion assessment and its 537 correlation with landslide events using remote sensing data and GIS: a case study at Penang Island, $538 \quad$ Malaysia. Environmental monitoring and assessment 184(2):715-727.

539 Rahmati, O., A. Haghizadeh, H. R. Pourghasemi, and F. Noormohamadi. 2016. Gully erosion 540 susceptibility mapping: the role of GIS-based bivariate statistical models and their comparison. $541 \quad$ Natural Hazards 82(2):1231-1258.

542 Van Remortel, R. D., R. W. Maichle, and R. J. Hickey. 2004. Computing the LS factor for the Revised 543 Universal Soil Loss Equation through array-based slope processing of digital elevation data using a $544 \quad$ C++ executable. Computers \& Geosciences 30(9-10):1043-1053.

545 Renard, K. G., G. R. Foster, G. A. Weesies, and J. P. Porter. 1991. RUSLE: Revised universal soil loss 
equation. Journal of soil and Water Conservation 46(1):30-33.

547 Renard, K. G., and J. R. Freimund. 1994. Using monthly precipitation data to estimate the R-factor in the 548 revised USLE. Journal of hydrology 157(1-4):287-306.

549

550

551

Ruysschaert, G., J. Poesen, G. Verstraeten, and G. Govers. 2007. Soil loss due to harvesting of various crop types in contrasting agro-ecological environments. Agriculture, ecosystems \& environment 120 (2007):153-165.

Sadeghi, S. H., M. Zabihi, M. Vafakhah, and Z. Hazbavi. 2017. Spatiotemporal mapping of rainfall erosivity index for different return periods in Iran. Natural Hazards 87(1):35-56.

Samanta, R. K., G. S. Bhunia, and P. K. shit. 2016. Spatial modelling of soil erosion susceptibility mapping in lower basin of Subarnarekha river (India) based on geospatial techniques. Modeling Earth Systems and Environment 2(2):1-13.

Sharma, A., K. N. Tiwari, and P. B. S. Bhadoria. 2011. Effect of land use land cover change on soil erosion potential in an agricultural watershed (2011):789-801.

Silva, R. B. da, K. P. Lanças, E. E. V Miranda, F. A. de M. Silva, and F. H. R. Baio. 2009. Estimation and evaluation of dynamic properties as indicators of changes on soil structure in sugarcane fields of Sao Paulo State--Brazil. Soil and Tillage Research 103(2):265-270.

Tadesse, L., K. V Suryabhagavan, G. Sridhar, and G. Legesse. 2017. Land use and land cover changes and Soil erosion in Yezat Watershed, North Western Ethiopia. International soil and water conservation research 5(2):85-94.

Tadesse, T. B., and S. A. Tefera. 2020. Comparing potential risk of soil erosion using RUSLE and MCDA techniques in Central Ethiopia. Modeling Earth Systems and Environment(Lal 1993).

Talukdar, S., B. Ghose, R. Salam, S. Mahato, Q. B. Pham, N. T. T. Linh, R. Costache, M. Avand, and others. 2020. Flood susceptibility modeling in Teesta River basin, Bangladesh using novel 
ensembles of bagging algorithms. Stochastic Environmental Research and Risk Assessment (2020):1-24.

571 Tang, B., J. Jiao, Y. Zhang, Y. Chen, N. Wang, and L. Bai. 2020. The magnitude of soil erosion on 572 hillslopes with different land use patterns under an extreme rainstorm on the Northern Loess $573 \quad$ Plateau, China. Soil and Tillage Research 204 (2020):104716.

574 Tang, Q., Y. Xu, and S. J. Bennett. 2015. Assessment of soil erosion using RUSLE and GIS : a case study 575 of the Yangou watershed in the Loess Plateau, China. Environmental Earth Sciences(73):1715$576 \quad 1724$.

577 Towfiqul Islam, A. R. M., S. Talukdar, S. Mahato, S. Kundu, K. U. Eibek, Q. B. Pham, A. Kuriqi, and N. 578 T. T. Linh. 2020. Flood susceptibility modelling using advanced ensemble machine learning models. $579 \quad$ Geoscience Frontiers (2020).

580 581 582 583 584 585 586 587 588 589 590 591

Troeh, F. R., J. A. Hobbs, R. L. Donahue, and others. 1980. Soil and water conservation for productivity and environmental protection. Prentice-Hall, Inc.

Vaezi, A. R., H. A. BAHRAMI, S. H. R. Sadeghi, and M. H. Mahdian. 2008. Evaluating Erosivity Indices of the USLE, MUSLE, RUSLE and USLE-M Models in Soils of a Semi-Arid Region in Northwest of Iran (2008).

Vaezi, A. R., and S. H. R. Sadeghi. 2011. Evaluating the RUSLE model and developing an empirical equation for estimating soil erodibility factor in a semi-arid region. Spanish journal of agricultural research(3):912-923.

Vanacker, V., Y. Ameijeiras-mariño, J. Schoonejans, J. Cornélis, J. P. G. Minella, F. Lamouline, M. Vermeire, B. Campforts, J. Robinet, M. Van De Broek, P. Delmelle, and S. Opfergelt. 2019. Land use impacts on soil erosion and rejuvenation in Southern Brazil. Catena 178(March):256-266.

Wang, D., B. Fu, W. Zhao, H. Hu, and Y. Wang. 2008. Multifractal characteristics of soil particle size 
593 Wang, G., S. Wente, G. Z. Gertner, and A. Anderson. 2002. Improvement in mapping vegetation cover 594 factor for the universal soil loss equation by geostatistical methods with Landsat Thematic Mapper 595 images. International Journal of Remote Sensing 23(18):3649-3667.

596 Wischmeier, W. H. 1976. Use and misuse of the universal soil loss equation. Journal of soil and water $597 \quad$ conservation (1976).

598 Wulf, H., B. Bookhagen, and D. Scherler. 2010. Seasonal precipitation gradients and their impact on 599 fluvial sediment flux in the Northwest Himalaya. Geomorphology 118(1-2):13-21.

600 Yariyan, P., M. Avand, R. A. Abbaspour, M. Karami, and J. P. Tiefenbacher. 2020. GIS-based spatial 601 modeling of snow avalanches using four novel ensemble models. Science of the Total Environment 602 745 (2020):141008. A novel GIS-based ensemble technique for rangeland downward trend mapping as an ecological indicator change. Ecological Indicators 117 (2020):106591.

606 Zare, M., T. Panagopoulos, and L. Loures. 2017. Simulating the impacts of future land use change on soil 607 erosion in the Kasilian watershed, Iran. Land Use Policy 67(June):558-572. controlling soil erosion. Catena 83(1):76-86. 